\title{
Advances in the treatment of novel coronavirus disease (COVID-19) with Western medicine and traditional Chinese medicine: a narrative review
}

\author{
Abdulbaset Al-Romaima", Yinan Liao", Jie Feng, Xihui Qin, Guiming Qin \\ School of Pharmaceutical Science, Guangxi Medical University, Nanning, China \\ Contributions: (I) Conception and design: A Al-Romaima, Y Liao, J Feng; (II) Administrative support: J Feng; (III) Provision of study materials or \\ patients: All authors; (IV) Collection and assembly of data: A Al-Romaima, Y Liao, J Feng; (V) Data analysis and interpretation: All authors; (VI) \\ Manuscript writing: All authors; (VII) Final approval of manuscript: All authors. \\ \#These authors contributed equally to this work. \\ Correspondence to: Jie Feng. School of Pharmaceutical Sciences, Guangxi Medical University, Shuangyong Road 22, Nanning 530021, China. \\ Email: ezjiefeng@hotmail.com.
}

\begin{abstract}
In December 2019, the coronavirus disease 2019 (COVID-19) caused by the novel severe acute respiratory syndrome coronavirus 2 (SARS-CoV-2) was discovered. Since its emergence, COVID-19 has been outbreaking rapidly worldwide, where the virus has so far caused the death of hundreds of thousands and infected more than a million, what has been called a pandemic by the World Health Organization (WHO). According to the WHO-Coronavirus disease 2019 Situation Report-142, by June 10, 2020, there are 7,145,539 confirmed cases and 408,025 deaths. There is an urgent need to develop a suitable specific medicine against this novel coronavirus; therefore, scientists and researchers around the world are making great efforts endeavoring to discover an efficient specific medication for COVID-19 treatment. Given the similarity of the novel coronavirus with previous epidemic viruses, namely, the acute respiratory syndrome coronavirus (SARS-CoV) and the Middle East respiratory syndrome coronavirus (MERS-CoV), previously tested drugs could potentially work against the novel coronavirus. In this narrative review, we aim to summarize and discuss the effectiveness of current Western medicine and traditional Chinese medicine options for COVID-19 treatment based on the overview of the scientific literature. Some Western medicines including remdesivir, chloroquine, hydroxychloroquine, favipiravir, lopinavir/ritonavir, and arbidol, as well as some traditional Chinese medicine (TCM) such as Qingfei Paidu decoction, Yupingfeng, Lianhua Qingwen, and TCM injections have revealed a relative activity against SARS-CoV-2 in vitro, in observational studies, and in clinical trials. However, further extensive studies and clinical trials including double-blind and randomized clinical trials, with a higher number of patients, are necessary to confirm the activity of these medicines. There are several ongoing trials conducted on the drugs of COVID-19, and the results are urgently needed to make a suitable treatment recommendation.
\end{abstract}

Keywords: Coronavirus disease 2019 (COVID-19); coronavirus; treatment; traditional Chinese medicine (TCM)

Submitted Apr 30, 2020. Accepted for publication Aug 28, 2020.

doi: $10.21037 /$ jtd-20-1810

View this article at: http://dx.doi.org/10.21037/jtd-20-1810

Coronaviruses (CoVs) are large, enveloped, positivestranded RNA viruses of zoonotic origin that belong to the Coronaviridae family of the Nidovirales order, and can be divided into four types: $\alpha, \beta, \delta$, and $\gamma \mathrm{CoVs}(1,2) . \alpha$ and $\beta$ CoVs chiefly infect mammals, while $\delta$ and $\gamma \mathrm{CoVs}$ predominantly infect birds (3). Human $\mathrm{CoVs}$ include $\alpha$-CoVs, $\beta$-CoVs, MERS-CoV, SARS-CoV, and 2019 novel coronavirus $(1,3)$. SARS-CoV, MERS-CoV, and SARS- 
CoV-2 are $\beta$-coronaviruses that infect the respiratory tract and cause pneumonia in humans (4).

SARS-CoV-2 is found responsible for the COVID-19 disease, which has rapidly spread around the world. The rapid growth in the number of patients caused widespread panic and commotion among the population. Furthermore, the rapid growth in the number of patients caused widespread panic and commotion among the population. Individuals of any age are predisposed to SARS-CoV-2, particularly the elderly and those with underlying chronic diseases (heart disease, diabetes, or lung disease) that are easy to become severe cases (5). By January 30, 2020, the WHO declared the epidemic to be a public health emergency of international alarm in the second meeting of the Emergency Committee (6). It was recommended that the corresponding vaccine and specific antiviral drug should be obtained as soon as possible (6). Nevertheless, the development of these drugs will take months or even years. The situation of COVID-19 is progressing quickly, with the cases count currently growing into the hundreds of thousands, what has been called a pandemic by the WHO (7). By June 10, 2020, based on the WHO-COVID-19 Situation Report, more than seven million are confirmed cases and more than four hundred thousand are deaths (8).

The sequencing of the entire genome of SARS-CoV-2 was discovered and discharged to open databases, exhibiting rapid data sharing during the outbreak response. Initial analyses revealed that SARS-CoV-2 has some amino acid similarity to SARS-CoV and can utilize the angiotensinconverting enzyme 2 (ACE2) as a receptor (2). This has huge ramifications for foreseeing pandemic possible pushing forward (2). Most Coronaviruses share comparable viral structure, comparable infection pathway, and a similar $\mathrm{S}$ protein structure, which suggests that research strategies already developed for other coronaviruses ought to be appropriate for the COVID-19 (9).

Like SARS and MERS, the SARS-CoV-2 genome encodes non-structural proteins, structural proteins, and accessory proteins. The non-structural proteins include RNA- dependent RNA polymerase ( $\mathrm{RdRp}$ ), papain-like protease, 3-chymotrypsin-like protease, and helicase, which are key enzymes in the life cycle of viruses. In contrast, structural proteins include the spike glycoprotein that is crucial for the interactions of the virus-cell receptor during viral entry MERS $(10,11)$. Therefore, these proteins were perceived as appealing to create antiviral agents against SARS and MERS2 (10). Preliminary analyses of genomic sequences from SARS-CoV-2 demonstrated that the catalytic sites of its enzymes that could be antiviral targets are exceptionally conserved, and share an elevated level of arrangement comparability with the related SARS and MERS enzymes (11). Besides, analyses of protein structure suggest that critical drug-binding pockets in viral enzymes are presumably preserved across SARS-CoV-2, SARS, and MERS $(12,13)$. Therefore, it is rational to consider repurposing present MERS and SARS inhibitors for COVID-19 treatment.

Since the emerging COVID-19, many scientific studies and clinical trials about therapy strategies have been published, but knowledge about COVID-19 therapy is still limited. Currently, there is an urgent necessity for an efficient treatment strategy to control the clinical deterioration of COVID-19 patients. In this article, we aim to summarize, analyze and discuss the effectiveness of current Western medicine and traditional Chinese medicine options for the treatment of COVID-19 based on an overview of the current scientific literature. Moreover, we discuss selected approved medicines that have already been verified in research studies or clinical trials for other viral diseases.

We present the following review in accordance with the Narrative Review reporting checklist (available at http:// dx.doi.org/10.21037/jtd-20-1810).

\section{Methods}

We searched the bibliographic databases and search engines including PubMed, Science Direct, Springer, and Google Scholar for English-language sources, while, Chinese National Knowledge Infrastructure (CNKI) was searched for Chinese-language sources. We also searched the official websites of the following organizations: the WHO (www.who.int/), Centers for Disease Control and Prevention (CDC, www.cdc.gov/), National Institute for Health and Clinical Excellence (NICE, www.nice.org.uk/), National Administration of Traditional Chinese Medicine (www.satcm.gov.cn/), National Health Commission of the People's Republic of China (NHC, www.nhc.gov.cn/), and Chinese government website (https://www.gov.cn/). The search terms included coronavirus, pneumonia, severe acute respiratory syndrome coronavirus 2, SARS-CoV-2, 2019-nCoV, SARS-CoV, MERS-CoV, and COVID-19 in combination with antiviral agents, drugs, medicines, treatment, therapy, and traditional Chinese medicine (TCM). We searched the current literature conducted on the drugs of COVID-19 from virus emergence time 
until May 2020. Additionally, we searched for literature that conducted on the therapeutic drugs of SARS-CoV (From 2003 to 2019) and MERS (From 2012 to 2019), and we included only the literature related to drugs that declared activity against these two previous viruses and have repurposed for COVID-19 treatment.

\section{Search strategy}

We searched the databases and engines mentioned above. The literature in English and Chinese languages were included, and the literature in other languages were excluded. All types of studies were evaluated including clinical trials, in vitro study, case-studies, systematic reviews, expert committees, and clinical guidelines. The combination of the following key words was used for electronic search: ("COVID-19" OR "2019 novel coronavirus disease" OR "COVID19" OR "COVID-19 pandemic" OR "SARS-CoV-2 infection" OR "COVID-19 virus disease" OR "2019 novel coronavirus infection" OR "2019-nCoV infection" OR "coronavirus disease 2019" OR "coronavirus disease-19" OR "2019-nCoV disease" OR "COVID-19 virus infection") AND ("SARS Virus" OR "Severe Acute Respiratory Syndrome Virus" OR "SARSRelated Coronavirus" OR "SARS Related Coronavirus" OR "SARS-CoV" OR "SARS Coronavirus" OR "Severe acute respiratory" OR "syndrome-related coronavirus" OR "Severe acute respiratory syndrome related coronavirus" OR "SARSAssociated Coronavirus" OR "SARS Associated Coronavirus") AND ("Coronavirus Infections" OR "Coronavirus Infection" OR "Middle East Respiratory Syndrome" OR "MERS (Middle East Respiratory Syndrome)") AND ("Antiviral Agents" OR "Agents, Antiviral” OR "Antivirals" OR "Antiviral Drugs" OR "Drugs, Antiviral”) AND ("Drug Therapy" OR "Therapy, Drug" OR "Drug Therapies" OR "Therapies, Drug" OR "Chemotherapy" OR "Chemotherapies" OR "Pharmacotherapy" OR "Pharmacotherapies") AND ("Medicine, Chinese Traditional" OR "Traditional Chinese Medicine" OR "Traditional Medicine, Chinese" OR "Chinese Traditional Medicine" OR "Chinese Medicine, Traditional"). The initial literature search identified 1530 articles, of which 95 articles were included in this narrative review.

\section{Results and discussion}

\section{Western medicines}

\section{Remdesivir}

Remdesivir is an investigational nucleotide analogue inhibitor of the RdRp enzyme (14) that integrates into budding viral RNA chains and causes premature termination (15). Remdesivir displays a broad spectrum of antiviral action against many RNA viruses $(16,17)$, including SARS-CoV and MERS-CoV (18), which are structurally similar to SARS- CoV-2. It has proved effective on EBOV infections in a human clinical trial (19). It has demonstrated that remdesivir inhibits the activity of SARS-CoV and MERS-CoV which can replicate in human epithelial cells and mediate entry via human $\mathrm{CoV}$ receptors, and resistance mutations have not been identified $(18,20)$. In preclinical trials, remdesivir has shown essential activity against coronavirus and a great genetic barrier to resistance (21).

Recently, an in vitro study established that remdesivir inhibited SARS-CoV-2 with a half-maximal effective concentration $\left(\mathrm{EC}_{50}\right)=0.77 \mu \mathrm{M}$ and a half-cytotoxic concentration $\left(\mathrm{CC}_{50}\right)$ greater than $100 \mu \mathrm{M}$ in Vero E6 cells (22). In the United States, the first COVID-19confirmed case has recovered after treatment with remdesivir intravenously in January 2020 (23). A recent study on a cohort of patients hospitalized with severe complications related to SARS-CoV-2 infection revealed clinical improvement in most patients after the compassionate use of remdesivir (24). A clinical trial (NCT04252664) in China is ongoing to evaluate the activity of remdesivir in COVID-19-infected; the data from this trial will be reported by May 2020 (25). By April 29, 2020, Gilead Sciences Company reported the preliminary results of Phase 3 SIMPLE trial to evaluate 5- and 10-day dosing durations of the antiviral remdesivir in hospitalized patients with severe COVID-19 disease, in which preliminary results revealed that at least $50 \%$ of patients treated with a 5 -day dosage of remdesivir improved and more than half were discharged from the hospital within 14 days. The company said that the study also showed that patients receiving the remdesivir for 10 days achieved similar improvement in clinical status compared with those taking the drug for 5 days (26). The recommended dose of remdesivir is shown in Table 1.

\section{Lopinavir/ritonavir (LPV/r)}

Lopinavir and ritonavir are protease inhibitors antiviral agents that can inhibit the replication of viruses and are used for acquired immunodeficiency syndrome (AIDS) treatment. They are currently formulated as a combination, in which ritonavir inhibits the metabolism of CYP3Amediated of lopinavir. This results in extending exposure to this drug, as well as enhanced patient compliance 


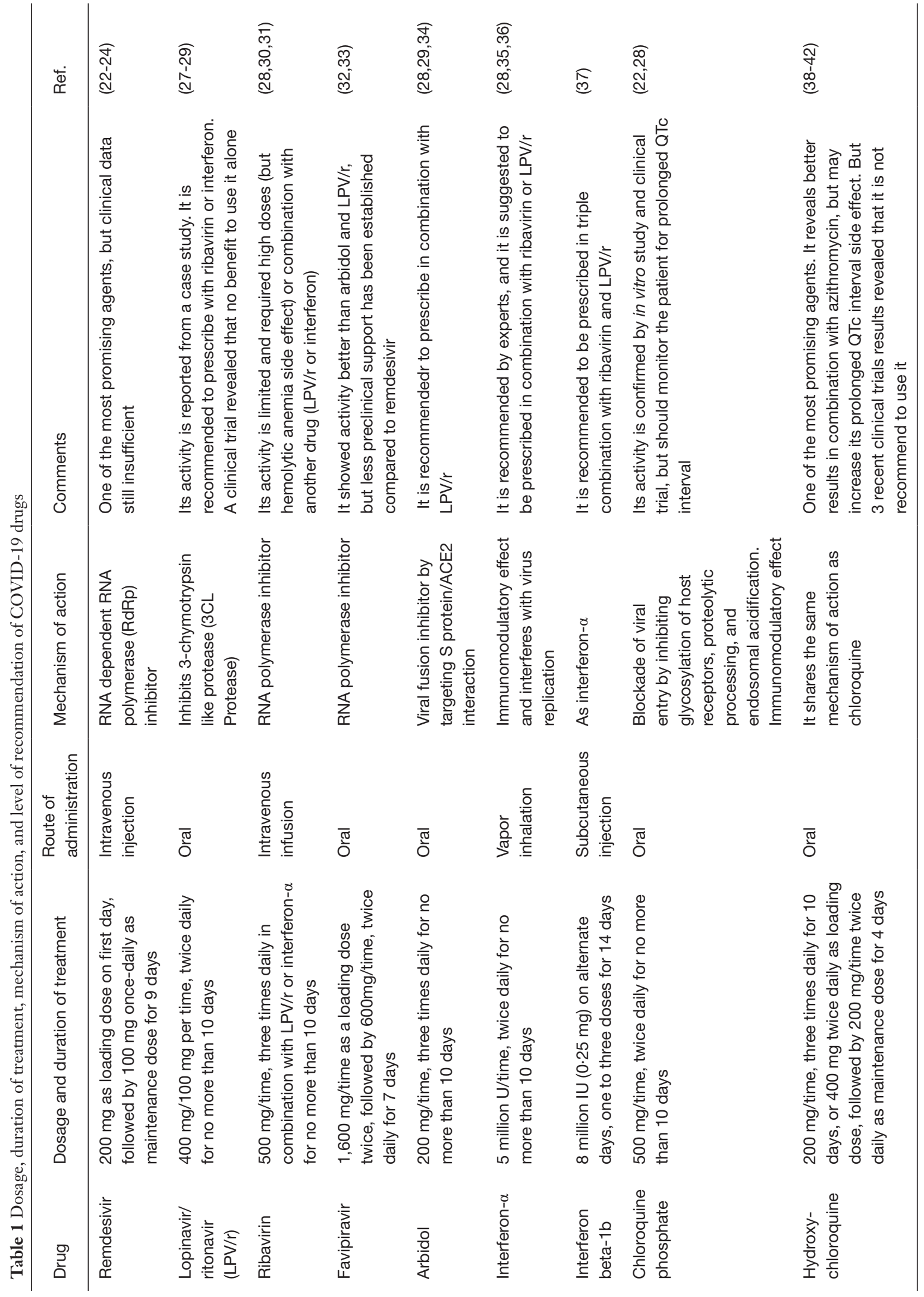


due to diminished pill burden; LPV/r is generally well tolerated (43). Recently, it was found that Lopinavir can inhibit 3CL protease of SARS-CoV-2 (44).

Many previous studies declared that receiving LPV/r either alone or in combination with antiviral helped in the SARS and MERS treatment, leading to a decrease in the incidence or mortality of acute respiratory distress syndrome (ARDS) (45-48). Furthermore, a recent systematic review indicated that the early use of LPV/r regimen could diminish the mortality of SARS and MERS, and reduce the dose steroids. Consequently, it was concluded that LPV/r could be used as a component of the experimental regimen to treat COVID-19 pneumonia. However, if the early treatment window is missed, there will be no important activity in their late administration (49). Thus, it is strongly suggested that preliminary real-world trials should be carried out to explore the true clinical effects of LPV/r in COVID-19 patients. In Korea, a new case study demonstrated that patients with COVID-19 pneumonia treated with $\mathrm{LPV} / \mathrm{r}$, the viral load was reduced, and the clinical symptoms improved during the treatment, no virus at all were reported to the extent that very small viral titers or no virus at all were reported (27). In China, LPV/r combination is recommended for novel coronavirus treatment, and it is included in the guidelines on the diagnosis and treatment of COVID-19 issued by NHC (Trial 7th edition) (28). On the contrary, a recent randomized controlled trial of $\mathrm{LPV} / \mathrm{r}$ in adults hospitalized with severe COVID-19 has carried out, and the results revealed that no benefit was observed with $\mathrm{LPV} / \mathrm{r}$ treatment further than standard care (50). The dose of LPV/r that can be considered for COVID-19 treatment is shown in Table 1 .

\section{Ribavirin}

Ribavirin is a guanosine analogue antiviral drug that is phosphorylated intracellularly by host cell enzymes. It interferes with guanosine triphosphate synthesis to block the capping of viral messenger RNA and to inhibit the viral RdRp enzyme of certain viruses (43). In a previous study, the activity of ribavirin on replication of SARS$\mathrm{CoV}$ was systematically tested in a panel of SARS$\mathrm{CoV}$ permissive cell lines, in which ribavirin was shown to inhibit SARS-CoV replication in five different cell types of animal or human origin at therapeutically realizable concentrations (51,52). Ribavirin can function synergistically in combination with lopinavir/ritonavir, and the combination of these three agents has been used against SARS and MERS (53). A recent study on LPV/r alone was not mainly remarkable, suggesting that triple therapy of LPV/r with ribavirin may be needed (53). In a virtual screening study for repurposing many drugs against SARSCoV-2 main protease (Mpro), ribavirin revealed a potent binding to SARS-CoV-2 Mpro (30). A recent molecular docking study showed that ribavirin was able to bind tightly with the SARS-CoV-2 RdRp, with a binding energy of $-7.8 \mathrm{kcal} / \mathrm{mol}$. Consequently, it can oppose the polymerase function, and it is proposed to contribute as a potent drug against SARS-CoV-2 (31). Ribavirin is included in the guideline issued by NHC (7th edition) in a dose, as shown in Table 1, and it was suggested to be used in combination with lopinavir/ritonavir or interferon (28).

\section{Favipiravir}

Favipiravir is a guanine analog antiviral drug that can efficiently inhibit the RdRp enzyme of RNA viruses such as Ebola, yellow fever, and influenza (12). Thus, favipiravir might have a likely antiviral effect on SARS-CoV-2, which is an RNA virus. A recent study stated that favipiravir has efficacy against SARS-CoV-2 $\left(\mathrm{EC}_{50}=61.88 \mu \mathrm{M}\right.$ in Vero E6 cells) (22). On February 14, a clinical trial introduced by the Clinical Medical Research Center of the National Infectious Diseases and the Third People's Hospital of Shenzhen on favipiravir for COVID-19 treatment accomplished promising preliminary results, in which a total of 80 patients showed that favipiravir has more strong antiviral activity than that of LPV/r (32). In March 2020, a clinical trial in Wuhan demonstrated that favipiravir could be considered as a preferred drug for COVID-19 treatment compared with arbidol due to its higher seven day's clinical recovery rate and more efficiently diminished the cough and fever incidence (33). According to the expected synergistic effect of viral inhibition and immune enhancement, a clinical trial (ChiCTR2000029600) has recruited patients to evaluate the efficacy of favipiravir plus interferon- $\alpha$ against SARS-CoV-2. Currently, Russia's Ministry of Health has approved favipiravir for treatment of COVID-19 but the clinical trial results weren't shown (54).

\section{Arbidol}

Arbidol is a broad-spectrum antiviral agent that inhibits viral fusion and can be used to treat influenza viruses. Arbidol was shown to have a direct antiviral effect against SARS-CoV in early viral replication in vitro (55). Recently, a retrospective cohort study demonstrated that the combination of arbidol with LPV/r might delay the lung lesions progression and reduce the probability of respiratory 
and gastrointestinal transmission for declining the viral load of COVID-19. Besides, this combination treatment led to a considerable improvement of chest CT scans in 7 days (29). In Wuhan, China, a current study analyzed the clinical features of 69 cases with COVID-19 infection. In this study, the efficacy of arbidol was evaluated. The results showed that $33 \%$ of patients had been discharged in the arbidol-treated group, whereas $19 \%$ of patients have been discharged in the arbidol-untreated group. Besides, there were no deaths in the arbidol-treated group. Therefore, it appeared that arbidol treatment could improve the discharging rate and decrease the mortality rate (34). Arbidol has been included in the guideline issued by NHC (Trial 7 th edition) as a recommended agent for COVID-19 treatment in a standard dose as shown in Table 1 (46).

\section{Interferons}

Interferons are host cytokines that can exert complicated immunomodulatory, antiviral, and anti-proliferative effects. Interferon- $\alpha$ seems to work by intracellular signal stimulation following binding to specific cell membrane receptors, causing in inhibition of viral entry, translation, transcription, protein processing, maturation, and release. Besides, interferons increase expression of major histocompatibility complex antigens, enhance the phagocytic activity of macrophages, and augment cytotoxic $T$ cells proliferation and survival (43).

Many previous studies demonstrated the activity of interferon with ribavirin combination. Since the clinical activity of type I interferon or ribavirin alone as antiSARS-CoV is limited, a combination of these two drugs was investigated, and the consequent determination of the virus yield showed a significant synergistic antiSARS-CoV effect of the combination, suggesting the consideration of interferon- $\beta$ together with ribavirin for SARS treatment (52). The interferon- $\beta$ with ribavirin combination inhibits the replication of SARS-CoV in significantly reduced concentrations compared with either single treatment. This might enable reaching sufficient therapeutic plasma levels sufficient to inhibit the replication of SARS-CoV throughout the early phase of SARS and consequently prevent immunopathological damages (51). Therefore, interferon- $\alpha 2 b$ and ribavirin combination was used effectively as a primary treatment and prophylaxis in SARS (51). Furthermore, interferon- $\alpha 2 b$ and ribavirin combination was shown to have some in vitro synergistic activities against MERS-CoV (56). This combination was given to patients with severe MERS-CoV infection, and the patient's survival was increased (57). Additionally, a study case described the successful use of this combination in human MERS-CoVs (58). Thus, interferon plus ribavirin combination is included in the guideline issued by NHC ( 7 th edition) (28).

A recent study demonstrated that interferon- $\alpha$ could decrease the viral load in the early stage of infection which leads to relieving symptoms and reduces the progression of disease in COVID-19 patients (35). Moreover, an in vitro study described the sensitivity of SARS-CoV-2 and SARS-CoV to type I interferon (IFN-I) in Vero cells. The results demonstrated that both viruses maintain a similar replication in untreated Vero E6 cells, but SARS-CoV-2 has a significant decrease in viral replication following IFN-I pretreatment, thus suggesting that IFN-I may be used as prophylactic against SARS-CoV-2 (36). Moving forward, these data could provide valuable insights for both the treatment of COVID-19 and the development of novel animal models of disease (36). Recently, an openlabel randomized trial revealed that early triple combination antiviral therapy with interferon beta- $1 \mathrm{~b}, \mathrm{LPV} / \mathrm{r}$, and ribavirin was safe and more effective than LPV/r alone in alleviating symptoms and shortening the duration of viral shedding and hospital stay in patients with mild to moderate COVID-19 (37).

\section{Chloroquine and hydroxychloroquine}

Chloroquine is a widely used antimalarial and immunomodulatory medicine that has recently been described as an effective broad-spectrum antiviral agent $(59,60)$. It blocks viral infection by elevating the endosomal $\mathrm{pH}$ that is necessary for the virus-cell interaction, as well as interfering with the glycosylation of SARS-CoV cellular receptors (61). Moreover, chloroquine is efficient in precluding the spread of SARS-CoV in cell culture. An advantageous inhibition of virus spread was seen when the cells were either treated with chloroquine previously or after SARS-CoV infection (60). Therefore, the antiviral and anti-inflammatory effects of chloroquine may explain its strong activity in treating of COVID-19 pneumonia patients (62).

Recent study results revealed that chloroquine worked at both entry, and post-entry stages of the SARS-CoV-2 in Vero E6 cells and that it can block the virus infection at low-micromolar concentration with $\mathrm{EC}_{50}=1.13 \mu \mathrm{M}$ and $\mathrm{CC}_{50}$ greater than $100 \mu \mathrm{M}$. Chloroquine showed efficiency in inhibiting the replication of SARS-CoV-2 and can block the growth of this virus in vitro (22). In addition to its 
antiviral effect, chloroquine has an immune-modulating activity, which can augment its antiviral effect in vivo. After oral administration, chloroquine can be found in the entire body, including the lungs (22). On February 15, 2020, a conference was held, and participants, including regulatory authorities, specialists from government, and coordinators of clinical trials, agreed that chloroquine phosphate has strong activity against SARS-CoV-2. Two days after, the State Council of China held a news briefing demonstrating that chloroquine phosphate had revealed obvious efficacy and satisfactory safety in treating COVID-19 associated pneumonia in multicenter clinical trials conducted in China $(62,63)$. Several consequent clinical trials have been rapidly accompanied in China to test the efficiency and safety of chloroquine in the treatment of SARS-CoV-2 associated pneumonia in many hospitals in different cities. The results from over 100 patients have revealed that chloroquine phosphate is superior to the control treatment in preventing the exacerbation of pneumonia, improving lung imaging findings, inducing a virus-negative conversion, and diminishing the infection course. Severe side effects of chloroquine phosphate were not observed in the patients mentioned above (62). Moreover, chloroquine phosphate is included in the guideline issued by NHC (7th edition) to treat COVID-19 patients in a recommended dose, as shown in Table 1 (28).

Hydroxychloroquine, an analog of chloroquine, was reported to have activity against coronavirus in vitro in the previous SARS outbreak (64). The clinical safety of hydroxychloroquine during prolonged use is better than that of chloroquine, and there are fewer concerns about drug-drug interactions, which allows a higher daily dose. Hydroxychloroquine may be an ideal drug to treat the SARS-CoV-2 infection as it can inhibit the virus and help mediate the cytokine storm via its immunomodulatory effects (38). A recent in vitro study demonstrated that hydroxychloroquine is more potent than chloroquine at inhibiting SARS-CoV-2 in vitro (38). In this study the pharmacological activity of chloroquine and hydroxychloroquine was verified using SARSCoV-2 infected Vero cells, and the results showed that hydroxychloroquine $\left(\mathrm{EC}_{50}=0.72 \mu \mathrm{M}\right)$ had a more potent in vitro anti-SARS-CoV-2 activity than chloroquine $\left(\mathrm{EC}_{50}=5.47 \mu \mathrm{M}\right)(36)$. In France, confirmed COVID-19 patients were included in a clinical trial from the beginning of March to March 16, to take hydroxychloroquine in a dose of $600 \mathrm{mg}$ daily. The results revealed a considerable decline of the viral carriage at D6-post inclusion compared with controls and much lower average carrying duration than that of untreated patients (39). Viral clearance at day 6 was $70 \%(14 / 20)$ for the hydroxychloroquine group versus $12.5 \%(2 / 16)$ for the control group. It was also reported that the addition of azithromycin to hydroxychloroquine in six patients led to numerically higher viral clearance $(6 / 6$, $100 \%)$ compared with hydroxychloroquine monotherapy $(8 / 14,57 \%)$, thus suggesting that this combination has more activity than hydroxychloroquine alone (39). The recommended dose of hydroxychloroquine for COVID-19 treatment is shown in Table 1.

On the contrary, a retrospective cohort study of patients from a random sample of admitted patients with laboratoryconfirmed COVID-19 in 25 hospitals in New York State indicated that treatment with hydroxychloroquine, azithromycin, or both, compared with no treatment, was not significantly associated with differences in inhospital mortality (40). Furthermore, recent openlabel randomized controlled trial in patients admitted to hospital with mild to moderate COVID-19 has revealed that adding hydroxychloroquine to the current standard of care in patients with mainly persistent mild to moderate COVID-19 did not show additional benefits of virus elimination (41). Another randomized control trial, to investigate whether hydroxychloroquine can prevent symptomatic infection after SARS-CoV-2 exposure, has demonstrated that after high-risk exposure to COVID-19, hydroxychloroquine did not prevent illness compatible with COVID-19 or confirmed infection when used as postexposure prophylaxis within 4 days after exposure (42).

\section{Corticosteroids}

The use of corticosteroids for COVID-19 treatment is controversial. Reasonable utilization of glucocorticoids can considerably improve the clinical symptoms of SARS patients, decline the degree of disease progression, and accelerate the absorption of lung lesions; but it cannot reduce the length of the hospital stay $(65,66)$. Early constrained utilization of corticosteroids in $\mathrm{CoV}$ pneumonia might be efficient in decreasing the pulmonary lesions and viral replication (67); however, many previous studies revealed that the corticosteroids use in SARS patients caused significant side effects, including secondary severe viral, bacterial, or fungal infections because of the immunosuppressive effects, myopathy, and finally an increased risk of either mortality or intensive care support requiring mechanical ventilation (68-70).

Methylprednisolone is suitable for COVID-19 patients 
with rapid disease progression or severe ailments (71). Additionally, short-term moderate-dose corticosteroid plus immunoglobulin is useful for reversing the continued deterioration of COVID-19 patients who failed to respond to low-dose therapy (72). In China, systemic glucocorticosteroid is recommended by the guideline issued by NHC (7th edition) as a short-term use $(1-2 \mathrm{mg} / \mathrm{kg} / \mathrm{d}$, 3-5 d) of methylprednisolone, but it should be taken with caution $(28,73)$. It is recommended to avoid corticosteroid utilization with a prolonged high-dose $(67,71)$.

\section{Antibiotics}

Antibiotics are not prescribed to treat COVID-19 itself. However, bacterial pneumonia occurs during hospital treatment (especially in intubated ventilator-associated pneumonia in COVID-19 patients) (74), and the secondary infection reached $16 \%(11 / 68)$ among patients who died from SARS-CoV-2 in one series, which may require the use of antibiotics (75). Therefore, the WHO recommended that empiric antimicrobial therapy should be based on clinical diagnosis (community-acquired pneumonia, hospital-acquired pneumonia) (76). Recently, the guidelines on diagnosis and treatment of COVID-19 (7th edition) emphasized that COVID-19 patients should avoid blind or unsuitable utilization of antibiotics, especially the combination of broad-spectrum antibiotics (28). Therefore, it is necessary to evaluate the use of antibiotics appropriately. According to the patient's clinical condition, if secondary bacterial infections cannot be excluded, mild patients should be provided antibiotics for communityacquired pneumonia, such as azithromycin, amoxicillin, or fluoroquinolones; and severe patients should be given empiric antibiotic treatment covering all of the possible pathogens, reducing therapy until the pathogenic bacteria are clarified (71).

Azithromycin, a macrolide antibiotic, was demonstrated to be effective in vitro against Ebola and Zika viruses $(77,78)$. Besides, azithromycin is supposed to have good activity in preventing severe respiratory tract infections when it is administrated to patients with viral infection (79). A recent study proved the synergistic effect of azithromycin plus hydroxychloroquine, in which this combination revealed more efficiency in eliminating viruses for treating COVID-19 infection compared with hydroxychloroquine alone (39). Another antibiotic that has revealed some activity against coronavirus is teicoplanin. It is a glycopeptide antibiotic that used in the treatment of Grampositive bacteria, especially staphylococcal infections. It has shown efficiency against many viruses including SAR$\mathrm{CoV}$ and MERS (80,81). A recent study has revealed that teicoplanin effectively blocks the cell entry of 2019 novel coronavirus (82). Thus, teicoplanin is suggested to be a possible alternative for the treatment of SARS-CoV-2.

\section{Traditional Chinese medicine (TCM)}

TCM has a long history and has played a crucial role in the prevention and treatment of various epidemic ailments. In 2003, the intervention of TCM in the treatment of SARS patients achieved a noteworthy therapeutic activity (83). Throughout the SARS-CoV-2 therapy, over 4,900 medical staff of TCM were sent out to Hubei Province, and a TCM scheme was included in the guidelines on the diagnosis and treatment of COVID-19 issued by NHC $(84,85)$.

TCM specialists actively contributed to the entire rescue process and participated in treatment collectively. Thousands of COVID-19 patients were successfully treated by TCM (86). However, the Chinese government is counseling physicians to consider combining Western antiviral medicines with TCM in combating COVID-19 pneumonia. Based on the clinical trials and current results, we describe here the most effective prescribed TCM remedies in the treatment of COVID-19.

\section{Qingfei Paidu decoction (QFPDD)}

QFPDD, composed of Rhizoma Dioscoreae, Fructus aurantii immaturus, Asarum, Wrinkled giant hyssop, and other 17 TC compounds Table 2 (87), is officially recommended as a SARS-CoV-2 medicine suitable for the treatment of light, medium, heavy, and critical patients as mentioned in the guideline issued by NHC (Trial 7th edition) (28). The total survey effective rate was higher than $90 \%$ and verified by a clinical trial $(85,88)$.

Using Network Pharmacology, a study demonstrated that QFPDD's chief targeting organ is the lung. Among QFPDD's 790 putative targets, 232 are co-expressed with ACE2, which is the receptor of the novel coronavirus. By regulating a sequence of proteins co-expressed with ACE2 and a series of signaling pathways closely related to the occurrence and development of diseases, QFPDD plays a role in balancing immunity and eliminating inflammation. Furthermore, it may act as an antiviral agent by targeting ribosomal proteins that are necessary for viral replication, thus inhibiting both viral mRNA translation and a group of proteins that interact with viral proteins. Notably, the key targets were mainly enriched in two categories of 
Table 2 The components of TCMs (for reference only)

\begin{tabular}{|c|c|c|}
\hline TCM & Chinese medicine components & Reference \\
\hline Huoxiang Zhengqi & $\begin{array}{l}\text { The shell of areca nut }(5 \mathrm{~g}) \text {, Angelica dahurica }(5 \mathrm{~g}) \text {, Purple perilla }(5 \mathrm{~g}) \text {, Poria cocos }(5 \mathrm{~g}) \text {, } \\
\text { Pinellia rhizome fermented mass }(10 \mathrm{~g}) \text {, Rhizoma Atractylodis Macrocephalae (10 g), Dried } \\
\text { tangerine or orange peel }(10 \mathrm{~g}) \text {, Magnolia officinalis }(10 \mathrm{~g}) \text {, Ginger juice (10 g), Platycodon } \\
\text { grandiflorum (10 g), Wrinkled giant hyssop ( } 15 \mathrm{~g}) \text {, Radix Glycyrrhizae Preparata (12 g) }\end{array}$ & $(91)$ \\
\hline Xuebijing injection & $\begin{array}{l}\text { Carthamus tinctorious, Radix paeoniae rubrathe (unpeeled) root of common peony, Ligusticum } \\
\text { wallichii, The root of red-rooted salvia, Angelica sinensis }\end{array}$ & $(87,94)$ \\
\hline $\begin{array}{l}\text { Shenfu injection, } \\
\text { Reduning injection }\end{array}$ & Red ginseng, Root of Aconite; Artemisia apiacea, Honeysuckle, Cape jasmine & $(91)$ \\
\hline Tanreqing injection & Radix scutellariae, Bear gall powder, Cornu gorais, Honeysuckle, Forsythia & $(87)$ \\
\hline Xingnaojing injection & Musk, Radix curcumae, Borneol & $(91)$ \\
\hline
\end{tabular}

diseases: viral infections and lung damage, indicating that its therapeutic effect on SARS-CoV-2 may be based on the anti-virus and repair of lung injury properties (89). Besides, a recent study has proven that QFPDD can inhibit the arachidonic acid (AA) metabolic pathway which is principally used to synthesize inflammatory cytokines, and consequently, it has a benefit for inhibiting the release of inflammatory factors in the body alleviating the cytokine storm (95).

\section{Yupingfeng (YPF)}

YPF, which consists of Astragalus membranaceus, Fried Rhizoma Atractylodis Macrocephalae, and Saposhnikovia divaricate, has been used in the prevention of SARS- CoV-2 as recommended by the Multi-province Chinese Medicine Prevention Program (90). Recently, a pharmacologic study found that YPF can exert immune regulation and anti-inflammatory effects through a variety of action mechanisms (96). Furthermore, the results of the KEGG pathway analysis revealed that YPF might be useful for treating lung injury and virus infection. The enriched pathways indicated that the effect of YPF regulating immunity and eliminating inflammation might work through immune response and inflammatory response pathways, such as the PI3K/Akt, Ras, HIF-1, and MAPK signaling pathways. According to the prediction of molecular docking, YPF plays a prevention role, probably by inhibiting the binding of SARS-CoV-2 to ACE2 receptors (97).

\section{Huoxiang Zhengqi (HXZQ)}

The ingredients of HXZQ include Agastache rugosus, Licorice, Perilla leaf, Angelica dahurica, and six other TCM compounds Table 2 (91). HXZQ was recommended for SARS-CoV-2 prevention due to its antiviral, antiinflammatory, and immunomodulatory activities, as well as its ability to alleviate gastrointestinal discomfort (98). These properties of HXZQ have been shown by TCM theory and modern pharmacological studies (99-101). Moreover, clinical and pharmacological studies have also demonstrated that HXZQ has therapeutic effects on fever, nausea or vomiting, abdominal pain, and diarrhea related to viral infection, suggesting that HXZQ may also improve similar symptoms of COVID-19 (102-104). 


\section{Lianhua Qingwen (LHQW)}

The Chinese prescription LHQW contains Angelica dahurica, Purple perilla, Poria cocos, Pinellia rhizome fermented mass, Rhizoma Atractylodis Macrocephalae, and seven other TCM compounds Table 2. The guideline issued by NHC (Trial 7th edition) advocates the use of LHQW on patients during medical observation (28). A previous report revealed the mechanism of action for LHQW by virtual screening technology, and the results showed that the LHQW has a potential inhibitory effect on the AA metabolism pathway that translates into inhibiting the release of inflammatory factors (95). The latest in vitro studies have illustrated that the LHQW capsule can significantly inhibit the activity of new coronavirus, reduce the virus content in cell membrane and cytoplasm, inhibit the excessive activation of cytokines (92), and noticeably improve the symptoms of fever, cough, and fatigue in patients with COVID-19 (105). Recently, a study by the academician of the Chinese Academy of Sciences Zhong Nanshan and his team demonstrated that LHQW significantly inhibited SARS-CoV-2 replication in Vero E6 cells and decreased the production of pro-inflammatory cytokines (IL-6, TNF- $\alpha$, CXCL-10/IP-10, and CCL-2/ MCP-1) at the mRNA levels. Moreover, this study revealed that treatment with LHQW caused abnormal particle morphology of virion in cells (93).

Since the immune system of a SARS-CoV-2 patient is deteriorated, and bacterial infections are a severe risk, the antibacterial effect of LHQW might be of value in controlling secondary pulmonary infections (105). LHQW can improve the immune function of SARS-CoV-2 patients, relieve acute symptoms, improve clinical efficacy, and accelerate disease recovery. For these reasons, the China National Medical Products Administration (NMPA) has approved LHQW for the treatment of light and medium COVID-19 (106).

\section{TCM injections}

The guideline issued by NHC (Trial 7th edition) pointed out that the TCM injections are more beneficial in patients with heavy and critical SARS-CoV-2. The recommended TCM injections include Xuebijing injection, Shenfu injection, Reduning injection, Tanreqing injection, and Xingnaojing injection (28). The Xuebijing injection contains Carthamus tinctorious, Radix paeoniae rubrathe, Ligusticum wallichii, the root of red- rooted salvia, and Angelica sinensis. Previous research showed that this injection has many pharmacological effects such as antagonizing endotoxin, inhibiting inflammatory response, improving immune function, regulating blood coagulation balance, and protecting tissues and organs (94).

Recently, Xuebijing injection has been approved by NMPA for the treatment of heavy and critical COVID-19 (107), in which it can play crucial roles as an anti-inflammatory, regulating blood coagulation, vascular endothelial protection, and improving immunity (108-110). Network pharmacology indicated that the mechanism of Xuebijing injection might work through the combined action of multiple components, multiple targets, and multiple pathways (111). In addition to targeting the 3CL hydrolase of SARS-CoV-2, the Xuebijing injection boosts the host's immunity and anti-infection ability after virus invasion (111). For adult viral pneumonia, Tanreqing injection has benefits in terms of effective rate, chest radiograph change time, and the average length of hospital stay (112). It is recommended to use TCM injections combined with Western drugs and other treatment methods to control the disease progression, suppress the cytokine storm, and reduce the mortality of critically ill patients (113).

\section{Other TCMs}

In addition to the drugs mentioned above, many other TCM drugs can play critical roles in the treatment of COVID-19. Jinhua Qinggan Granule is suitable for the treatment of patients with mild pneumonia. It can significantly reduce the clinical symptoms of fever, cough, fatigue, and expectoration in patients with mild coronavirus pneumonia as well as relieve psychological anxiety (114). Besides, Jinhua Qinggan Granules have been approved for the treatment of COVID-19, which can well meet the needs of clinical treatment (115). Huashi Baidu Fang and Xuanfei Baidu Fang are effective prescriptions summarized by academician Huang Luqi and academician Zhang Boli. According to clinical observations in the frontline of Wuhan, both drugs can block the development of the disease and improve symptoms, thus shortening the course of the disease. Recently, Huashi Baidu granules and Qingfei Paidu granules have been approved by NMPA and obtained the approval for national clinical trials (115).

\section{Conclusions}

The novel coronavirus is spreading rapidly and is considered a global pandemic that is causing terror worldwide. Knowledge on how to treat COVID-19 is still limited, and there is an urgent need to find a potentially effective medicine. Thus, scientists around the world are 
actively exploring drugs that can be significantly effective in combating COVID-19. Based on the literature we have overviewed, that there is no specific effective drug for COVID-19 treatment to date. Recent research studies and clinical trial results revealed relative activity of some drugs in the treatment of COVID-19, and they are suggested for use the time being to treat the COVID-19 until an efficient anti-SARS-CoV-2 drug has been proven and established. The western medicines that inhibit RdRp enzyme (as remdesivir) are promising drugs for future treatment of COVID-19. A combination of 3CLpro inhibitors (as $\mathrm{LPV} / \mathrm{r}$ ), immunomodulatory agents (as interferon), and RNA polymerase inhibitor (as Ribavirin) might be a promising combination prospect for future therapy. TCM, with the advantages of the multi-target effect, had exhibited good effects in improving patients' symptoms, reducing inflammation, and regulating body immunity. In the future, with the improvement of TCMs' quality, more accurate researches on the mechanism, and the disclosure of effective clinical evidence, more opportunities will be given to TCMs. Therefore, it should be taken into consideration the combination of western medicine and TCM, they may prospect to be one of the best a promising effective strategy in the treatment of COVID-19. Actually, it is challenging to base a treatment decision in the absence of a complete research cycle and a clear vision of drug efficacy and safety. Further extensive studies and clinical trials including double-blind and randomized control trials, with a higher number of patients, are urgently needed to confirm the activity of these medicines. There are many ongoing clinical trials that are investigating the efficiency of single or combination therapy with the medicines mentioned in this review and new drugs are under development. The results of these trials are urgently required to make clear recommendations for the treatment of COVID-19.

\section{Acknowledgments}

Funding: This work was supported by the National Natural Science Foundation of China (81960706), the Guangxi First-class Discipline Project for Pharmaceutical Sciences (GXFCDP-PS-2018) and the Natural Science Foundation of Guangxi Province of China (No. 2017GXNSFAA198304).

\section{Footnote}

Reporting Checklist: The authors have completed the
Narrative Review reporting checklist. Available at http:// dx.doi.org/10.21037/jtd-20-1810

Peer Review File: Available at http://dx.doi.org/10.21037/jtd20-1810

Conflicts of Interest: All authors have completed the ICMJE uniform disclosure form (available at http://dx.doi. org/10.21037/jtd-20-1810). The authors have no conflicts of interest to declare.

Ethical Statement: The authors are accountable for all aspects of the work in ensuring that questions related to the accuracy or integrity of any part of the work are appropriately investigated and resolved.

Open Access Statement: This is an Open Access article distributed in accordance with the Creative Commons Attribution-NonCommercial-NoDerivs 4.0 International License (CC BY-NC-ND 4.0), which permits the noncommercial replication and distribution of the article with the strict proviso that no changes or edits are made and the original work is properly cited (including links to both the formal publication through the relevant DOI and the license). See: https://creativecommons.org/licenses/by-nc-nd/4.0/.

\section{References}

1. Zhu N, Zhang D, Wang W, et al. A novel coronavirus from patients with pneumonia in China, 2019. N Engl J Med 2020;382:727-33.

2. Paules CI, Marston HD, Fauci AS. Coronavirus infections-more than just the common cold. JAMA 2020;323:707-8.

3. Shen KL, Yang YH. Diagnosis and treatment of 2019 novel coronavirus infection in children: a pressing issue. World J Pediatr 2020;16:219-21.

4. Sohrabi C, Alsafi Z, O'Neill N, et al. World Health Organization declares global emergency: a review of the 2019 novel coronavirus (COVID-19). Int J Surg 2020;76:71-6.

5. US Centers for Disease Control and Prevention (CDC). Coronavirus disease 2019 (COVID- 19). Available online: https://www.cdc.gov/coronavirus/2019-ncov/specificgroups/high-risk- complications.html

6. Patel A, Jernigan DB. 2019-nCoV CDC Response Team. Initial public health response and interim clinical guidance for the 2019 novel coronavirus outbreak - United States, 
December 31, 2019-February 4, 2020. MMWR Morb Mortal Wkly Rep 2020;69:140-6.

7. World Health Organization. WHO Director-General's opening remarks at the media briefing on COVID-19. 11 March 2020. Available online: https://www.who.int/dg/ speeches/detail/who-director-general-s-opening-remarksat-the-media-briefing-on-covid-19---11-march-2020

8. World Health Organization. WHO-Coronavirus disease 2019 (COVID-19) Situation Report-142. Available online: https://www.who.int/docs/default-source/coronaviruse/ situation-reports/20200610-covid-19-sitrep-142. pdf?sfvrsn=180898cd_6

9. Yuan Y, Cao D, Zhang Y, et al. Cryo-EM structures of MERS-CoV and SARS-CoV spike glycoproteins reveal the dynamic receptor binding domains. Nat Commun 2017;8:15092.

10. Zumla A, Chan JF, Azhar EI, et al. Coronaviruses - drug discovery and therapeutic options. Nat Rev Drug Discov 2016;15:327-47.

11. Morse JS, Lalonde T, Xu S, et al. Learning from the past: possible urgent prevention and treatment options for severe acute respiratory infections caused by 2019-nCoV. Chembiochem 2020;21:730-8.

12. De Clercq E. New nucleoside analogues for the treatment of hemorrhagic fever virus infections. Chem Asian J 2019;14:3962-8.

13. Li G, Clercq E. Therapeutic options for the 2019 novel coronavirus (2019-nCoV). Nat Rev Drug Discov 2020;19:149-50.

14. Gordon CJ, Tchesnokov EP, Feng JY, et al. The antiviral compound remdesivir potently inhibits RNA-dependent RNA polymerase from Middle East respiratory syndrome coronavirus. J Biol Chem 2020;295:4773-9.

15. Warren TK, Jordan RO, Michael LO, et al. Therapeutic efficacy of the small molecule GS- 5734 against Ebola virus in rhesus monkeys. Nature 2016;531:381-5.

16. Siegel D, Hui H, Doerffler E, et al. Discovery and synthesis of a phosphoramidate prodrug of a pyrrolo[2,1-f] [triazin-4-amino] adenine c-nucleoside (GS-5734) for the treatment of Ebola and emerging viruses. J Med Chem 2017;60:1648-61.

17. Lo MK, Jordan R, Arvey A, et al. GS-5734 and its parent nucleoside analog inhibit Filo-, Pneumo-, and Paramyxoviruses. Sci Rep 2017;7:43395.

18. Sheahan TP, Sims AC, Graham RL, et al. Broad-spectrum antiviral GS-5734 inhibits both epidemic and zoonotic coronaviruses. Sci Transl Med 2017;9:3653.

19. Mulangu S, Dodd LE, Davey RT, et al. A randomized, controlled trial of Ebola virus disease therapeutics. N Engl J Med 2019;381:2293-303.

20. Tim S, Tony P. COVID-19 drug therapy - potential options. Clinical Drug Information 2020.

21. Agostini ML, Andres EL, Sims AC, et al. Coronavirus susceptibility to the antiviral remdesivir (GS-5734) is mediated by the viral polymerase and the proofreading exoribonuclease. mBio 2018;9:e0221-18.

22. Wang M, Cao R, Zhang L, et al. Remdesivir and chloroquine effectively inhibit the recently emerged novel coronavirus (2019-nCoV) in vitro. Cell Res 2020;30:269-71.

23. Holshue ML, Debolt C, Lindquist S, et al. First case of 2019 novel coronavirus in the United States. N Engl J Med 2020;382:929-36.

24. Grein J, Ohmagari N, Shin D, et al. Compassionate Use of Remdesivir for Patients with Severe Covid-19. N Engl J Med 2020;382:2327-36.

25. U.S National library of Medicine NIH clinical trial. Available online: https://clinicaltrials.gov/ct2/show/ NCT04252664

26. Gilead Sciences Company, Gilead Announces Results From Phase 3 Trial of Investigational Antiviral Remdesivir in Patients With Severe COVID-19. Available online: https://www.gilead.com/news-and-press/press-room/ press-releases/2020/4/gilead-announces-results-fromphase-3-trial-of-investigational-antiviral-remdesivir-inpatients-with-severe-covid-19

27. Lim J, Jeon S, Shin HY, et al. Case of the index patient who caused tertiary transmission of COVID-19 infection in Korea: the application of lopinavir/ritonavir for the treatment of COVID-19 infected pneumonia monitored by quantitative RT-PCR. J Korean Med Sci 2020;35:e79.

28. National Health Commission of the PRC. COVID-19 treatment and diagnosis guideline (7th version, trial). Available online: http://www.nhc.gov.cn/yzygj/s7653p/202 003/46c9294a7dfe4cef80dc7f5912eb1989.shtml

29. Deng L, Li C, Zeng Q, et al. Arbidol combined with LPV/ $\mathrm{r}$ versus LPV/r alone against corona virus disease 2019: a retrospective cohort study. J Infect 2020;81:e1-5.

30. Kandeel M, Al-Nazawi M. Virtual screening and repurposing of FDA approved drugs against COVID-19 main protease. Life Sci 2020;251:117627.

31. Elfiky AA. Ribavirin, Remdesivir, Sofosbuvir, Galidesivir, and Tenofovir against SARS-CoV-2 RNA dependent RNA polymerase (RdRp): A molecular docking study. Life Sci 2020;253:117592.

32. Third People's Hospital of Shenzhen. February 14, 2020. Favipiravir is more effective than Lopinavir/ritonavir in 
the treatment of COVID-19. Available online: http:// www.szdsyy.com/News/0a6c1e58-e3d0-4cd1-867ad5524bc59cd6.html. (in Chinese)

33. Chen C, Huang J, Cheng Z, et al. Favipiravir versus arbidol for COVID-19: a randomized clinical trial. MedRxiv 2020. Doi: 10.1101/2020.03.17.20037432

34. Wang Z, Yang B, Li Q, et al. Clinical Features of 69 Cases with Coronavirus Disease 2019 in Wuhan, China. Clin Infect Dis 2020;71:769-77.

35. Shen K, Yang Y, Wang T, et al. Diagnosis, treatment, and prevention of 2019 novel coronavirus infection in children: experts' consensus statement. World J Pediatr 2020;16:223-31.

36. Kumari G, Adam H, Craig S, et al. SARS-CoV-2 sensitive to type I interferon pretreatment. bioRxiv 2020. doi: 10.1101/2020.03.07.982264. Preprint.

37. Hung IF, Lung KC, Tso EY, et al. Triple combination of interferon beta-1b, lopinavir-ritonavir, and ribavirin in the treatment of patients admitted to hospital with COVID-19: an open-label, randomised, phase 2 trial. Lancet. 2020;395:1695-704.

38. Yao X, Ye F, Zhang M, et al. In Vitro Antiviral Activity and Projection of Optimized Dosing Design of Hydroxychloroquine for the Treatment of Severe Acute Respiratory Syndrome Coronavirus 2 (SARS-CoV-2). Clin Infect Dis 2020;71:732-9.

39. Gautret P, Lagier JC, Parola P, et al. Hydroxychloroquine and azithromycin as a treatment of COVID-19: preliminary results of an open-label non-randomized clinical trial. Int J Antimicrob Agents 2020;56:105949.

40. Rosenberg ES, Dufort EM, Udo T, et al. Association of Treatment With Hydroxychloroquine or Azithromycin With In-Hospital Mortality in Patients With COVID-19 in New York State. JAMA 2020;323:2493-502.

41. Tang W, Cao Z, Han M, et al. Hydroxychloroquine in patients with mainly mild to moderate coronavirus disease 2019: open label, randomised controlled trial. BMJ 2020;369:m1849.

42. Boulware DR, Pullen MF, Bangdiwala AS, et al. A Randomized Trial of Hydroxychloroquine as Postexposure Prophylaxis for Covid-19. N Engl J Med 2020;383:517-25.

43. Katzung BG, Masters SB, Trevor AJ. Basic and clinical pharmacology. 11th. New York: McGraw Hill Professional, 2009:864.

44. Huang J, Song W, Huang H, et al. Pharmacological Therapeutics Targeting RNA-Dependent RNA Polymerase, Proteinase and Spike Protein: From Mechanistic Studies to Clinical Trials for COVID-19. J
Clin Med 2020;9:1131.

45. Chan KS, Lai ST, Chu CM, et al. Treatment of severe acute respiratory syndrome with lopinavir/ritonavir: a multicentre retrospective matched cohort study. Hong Kong Med J 2003;9:399-406.

46. Chu CM, Cheng VC, Hung IF, et al. Role of lopinavir/ ritonavir in the treatment of SARS: initial virological and clinical findings. Thorax 2004;59:252-6.

47. Lai ST. Treatment of severe acute respiratory syndrome. Eur J Clin Microbiol Infect Dis 2005;24:583-91.

48. Meyer B, Basra A, Aberle S, et al. 1225: MERS-CoV disease associated ARDS - a case report. Critical Care Medicine 2015;43:308.

49. Jiang $\mathrm{H}$. The possibility of using lopinave/ritonawe (LPV/r) as treatment for novel coronavirus 2019nCov pneumonia: a quick systematic review based on earlier coronavirus clinical studies. Chin J Emerg Med 2020;29:182-6. (in Chinese).

50. Cao B, Wang Y, Wen D, et al. A Trial of LopinavirRitonavir in Adults Hospitalized with Severe Covid-19. N Engl J Med 2020;382:1787-99.

51. Morgenstern B, Michaelis M. Ribavirin and interferonbeta synergistically inhibit SARS- associated coronavirus replication in animal and human cell lines. Biochem Biophys Res Commun 2005;326:905-8.

52. Li H, Wang YM, Xu JY, et al. Potential antiviral therapeutics for 2019 novel coronavirus. Zhonghua Jie He He Hu Xi Za Zhi 2020;43:170-2.

53. Young BE, Ong SWX, Kalimuddin S, et al. Epidemiologic Features and Clinical Course of Patients Infected With SARS-CoV-2 in Singapore. JAMA 2020;323:1488-94.

54. The Russian Government, Russia's Ministry of Health. Available online: http://government.ru/en/news/39802/

55. Khamitov RA, Loginova SY, Shchukina VN, et al. Antiviral activity of arbidol and its derivatives against the pathogen of severe acute respiratory syndrome in the cell cultures. Vopr Virusol 2008;53:9-13.

56. Falzarano D, Emmie W, Martellaro C, et al. Inhibition of novel $\beta$ coronavirus replication by a combination of interferon- $\alpha 2 b$ and ribavirin. Sci Rep 2013;3:1686.

57. Mustafa S, Balkhy H, Gabere MN, Current treatment options and the role of peptides as potential therapeutic components for Middle East respiratory syndrome (MERS): a review. J Infect Public Health 2018;11:9-17.

58. Khalid M, Alrabiah F, Khan B, et al. Ribavirin and interferon$\alpha 2 \mathrm{~b}$ as primary and preventive treatment for Middle East respiratory syndrome coronavirus: a preliminary report of two cases. Antivir Ther 2015;20:87-91. 
59. Savarino A, Trani L, Donatelli I, et al. New insights into the antiviral effects of chloroquine. Lancet Infect Dis 2006;6:67-9.

60. Yan Y, Zou Z, Sun Y, et al. Anti-malaria drug chloroquine is highly effective in treating avian influenza A H5N1 virus infection in an animal model. Cell Res 2013;23:300-2.

61. Vincent MJ, Bergeron E, Benjannet S, et al. Chloroquine is a potent inhibitor of SARS coronavirus infection and spread. Virol J 2005;2:69.

62. Gao J, Tian ZX, Yang X. Breakthrough: Chloroquine phosphate has shown apparent efficacy in treatment of COVID-19 associated pneumonia in clinical studies. Biosci Trends 2020;14:72-3.

63. The National Health Commission of the People's Republic of China. Audio transcript of the news briefing held by the State Council of China on February 17, 2020. Available online: http://www.nhc.gov.cn/xcs/yqfkdt/202002/f12a62d 10c2a48c6895cedf2faea6e1f.shtml (accessed February 18, 2020). (in Chinese)

64. Biot C, Daher W, Chavain N, et al. Design and synthesis of hydroxyferroquine derivatives with antimalarial and antiviral activities. J Med Chem 2006;49:2845-9.

65. Zhao ZW, Zhang FC, Xu M, et al. Clinical analysis of 190 cases of outbreak with atypical pneumonia in Guangzhou in spring 2003. Zhonghua Yi Xue Za Zhi 2003;83:713-8.

66. Meng QH, Dong PL, Guo YB, et al. Use of glucocorticoid in treatment of severe acute respiratory syndrome cases. Chinese Journal of Preventive Medicine 2003;37:233-5. (in Chinese)

67. Jung K, Alekseev KP, Zhang XS et al. Altered pathogenesis of porcine respiratory coronavirus in pigs due to immunosuppressive effects of dexamethasone: implications for corticosteroid use in treatment of severe acute respiratory syndrome coronavirus. J Virol 2007;81:13681-93.

68. Auyeung TW, Lee JSW, Lai WK et al. The use of corticosteroid as treatment in SARS was associated with adverse outcomes: a retrospective cohort study. J Infect 2005;51:98-102.

69. Choi KW, Chau TN, Tsang O, et al. Outcomes and prognostic factors in 267 patients with severe acute respiratory syndrome in Hong Kong. Ann Intern Med 2003;139:715-23.

70. Franks TJ, Chong Y, Chui P, et al. Lung pathology of severe acute respiratory syndrome (SARS): a study of 8 autopsy cases from Singapore. Hum Pathol 2003;34:743-8.

71. Jin YH, Cai L, Cheng ZS, et al. A rapid advice guideline for the diagnosis and treatment of 2019 novel coronavirus (2019-nCoV) infected pneumonia (standard version). Mil
Med Res 2020;7:4.

72. Zhou ZG, Xie SM, Zhang J, et al. Short-term moderatedose corticosteroid plus immunoglobulin effectively reverses COVID-19 patients who have failed low-dose therapy. Preprints 2020;2020030065.

73. Du B, Qiu H, Zhan X, et al. Pharmacotherapeutics for the new coronavirus pneumonia. Zhonghua Jie $\mathrm{He} \mathrm{He} \mathrm{Hu} \mathrm{Xi}$ Za Zhi 2020;43:173-6.

74. Farkas J. COVID-19, Internet Book of Critical Care (IBCC) 2020. Available online: https://emcrit.org/ibcc/ covid19/

75. Ruan Q, Yang K, Wang WX, et al. Clinical predictors of mortality due to COVID-19 based on an analysis of data of 150 patients from Wuhan, China. Intensive Care Med 2020;46:846-8.

76. World Health Organization (WHO). Available online: https://apps.who.int/iris/handle/10665/330893

77. Madrid PB, Panchal RG, Warren TK, et al. Evaluation of Ebola Virus Inhibitors for Drug Repurposing. ACS Infect Dis 2015;1:317-26.

78. Bosseboeuf E, Aubry M, Nhan T, et al. Azithromycin inhibits the replication of Zika virus. J Antivir Antiretrovir 2018;10:6-11.

79. Bacharier LB, Guilbert TW, Mauger DT, et al. Early administration of azithromycin and prevention of severe lower respiratory tract illnesses in preschool children with a history of such illnesses: A randomized clinical trial. JAMA 2015;314:2034-44.

80. Zhou N, Pan T, Zhang J, et al. Glycopeptide antibiotics potently inhibit cathepsin $\mathrm{L}$ in the late endosome/ lysosome and block the en-try of Ebola virus, Middle East respiratory syndrome coronavirus (MERS-CoV), and severe acute respiratory syndrome coronavirus (SARSCoV). J Biol Chem 2016;291:9218-32.

81. Colson P, Raoult D. Fighting viruses with antibiotics: an overlooked path. Int J Antimicrob Agents 2016;48:349-52.

82. Zhang J, Ma X, Yu F, et al. Teicoplanin potently blocks the cell entry of 2019-nCoV. bioRxiv 2020. doi: 10.1101/2020.02.05.935387.

83. World Health Organization (WHO). SARS: Clinical trials on treatment using a combination of traditional Chinese medicine and Western medicine. (2004). Available online: https://apps.who.int/iris/ bitstream/handle/10665/43029/9241546433_eng. pdf? sequence $=1 \&$ amp;isAllowed $=y$

84. National Health Commission of the PRC. COVID-19 treatment and diagnosis guideline (6th version, trial). Available online: http://www.nhc.gov.cn/xcs/zhengcwj/202 
002/8334a8326dd94d329df351d7da8aefc2.shtml

85. The Central People's Government of the People's Republic of China. Available online: http://www.gov.cn/ xinwen/2020-03/24/content_5494742.htm

86. Publicity Department of the People's Republic of China. Press conference of the joint prevention and control mechanism of state council on Feb 17, 2020. Available online: http://www.nhc.gov.cn/xcs/fkdt/202002/f12a62d1 0c2a48c6895cedf2faea6e1f.shtml (accessed Feb 23, 2020). (in Chinese)

87. Song JX, Zhang ZH, Zhao SM, et al. Patent information analysis on traditional Chinese medicine for prevention and treatment of COVID-19. Drug Evaluation Research 2020;43:565-90. (in Chinese)

88. Lu ZZ, Lu XS. Qingfei Paidu Decoction Demonstrates the Anti-Epidemic Effects and Self-Confidence of Traditional Chinese Medicine. Journal of Traditional Chinese Medicine 2020;61:833-4. (in Chinese)

89. Zhao J, Tian SS, Yang J, et al. Investigating mechanism of Qing-Fei-Pai-Du-Tang for treatment of COVID-19 by network pharmacology. Chinese Traditional and Herbal Drugs 2020;51:829-35. (in Chinese)

90. Xu X, Zhang Y, Li X, et al. Analysis on prevention plan of coronavirus disease 2019 (COVID-19) by traditional Chinese medicine in various regions. Chinese Traditional and Herbal Drugs 2020;51:866-72. (in Chinese)

91. Xu HY, Zhang YQ, Liu ZM, et al. ETCM: an encyclopaedia of traditional Chinese medicine. Nucleic Acids Res 2019;47:D976-82.

92. Jia ZH, Li HR, Chang LP, et al. Historical review and reflection about application of traditional Chinese medicine in epidemic diseases. Chinese Journal of Experimental Traditional Medical Formulae 2020;26:1-7. (in Chinese)

93. Runfeng L, Yunlong H, Jicheng H, et al. Lianhuaqingwen exerts anti-viral and anti-inflammatory activity against novel coronavirus (SARS-CoV-2). Pharmacol Res 2020;156:104761.

94. Li LJ, Ma R, Cao Y. Research progress on pharmacological mechanism of Xuebijing injection in treatment of sepsis. Drug Evaluation Research 2018;41:1548-53. (in Chinese)

95. Ren Y, Yao MC, Huo XQ, et al. Study on treatment of "cytokine storm" by anti-SARS-CoV- 2 prescriptions based on arachidonic acid metabolic pathway. China Journal of Chinese Materia Medica 2020;45:1225-31.

96. Wang QN, Lu WL, Li JM, et al. Advances in Experimental Research and Clinical Application of Yupingfeng Powder. Chinese Archives of Traditional Chinese Medicine 2019.
Available online: http://kns.cnki.net/kcms/detail/21.1546. R.20191210.1428.105.html (in Chinese)

97. Zhan QZ, Huang YJ, Lin SH, et al. Study on active compounds of Yupingfeng San for prevention of coronavirus disease 2019 (COVID-19) based on network pharmacology and molecular docking. Chinese Traditional and Herbal Drugs 2020;51:1731-40.

98. Wang YQ, Hao YM. Discussion on prevention and treatment of COVID-19 with traditional Chinese medicine from immunoregulation. Shanghai Journal of Traditional Chinese Medicine 2020;54:13-7. (in Chinese)

99. Zhao YY, Xie W, Chen BT, et al. Research on relativity between hemorrheology indexes and the levels of endothelin and thromboxane B2 in rats with lung qi deficiency syndrome. Journal of Anhui Traditional Chinese Medical College 2003;22:44-6.

100.Zong SB, Lv YZ, Sun L, et al. Effect of Jiawei Huoxiang Zhengqi soft capsule on chemotactic cytokine of colitis in rats. Pharm Clin Res 2015;23:229-31.

101.He YH, Luo XJ, Qian XW, et al. Effects of Huoxiang Zhengqi liquid on enteric mucosal immune responses in mice with bacillusdysenteriaeand salmonella typhimurium induced diarrhea. Zhongguo Zhong Yao Za Zhi 2007;32:2397-400.

102.Zhao HJ, Guo LP, Yang FW, et al. Huoxiang Zhengqi formulas for treatment of gastrointestinal type cold: a systematic review and Meta-analysis. Zhongguo Zhong Yao Za Zhi 2017;42:1495-9.

103. Han XP. The therapeutic effect of oseltamivir phosphate assisted Huoxiang Zhengqi liquid on influenza. Chin J Mod Drug Appl 2016;10:139-41.

104. Wang MY. Huoxiang Zhengqi powder in treating 22 cases of Norovirus infectious diarrhea. Nei Mongol Journal of Traditional Chinese Medicine 2010;29:8.

105.Li HR, Chang LP, Wei C, et al. Theoretical research basis and clinical efficacy of Lianhua Qingwen in treating novel coronavirus pneumonia. World Chinese Medicine 2020;15:332-5. (in Chinese)

106. News. Available online: http://www.yiling.cn/news/ gsyw/20200414/9224.html

107. Tianjin Municipal People's Government. Available online: http://www.tj.gov.cn/xw/qx1/202004/t20200423_3672910. html

108. Ma ST, Yu H, Zhang HL, et al. Study on the Pharmacodynamic Material Basis of Xuebijing Formula and the Multi-target Action Effect of Sepsis. Zhongguo Zhong Xi Yi Jie He Za Zhi 2015;35:1351-5. (in Chinese) 109.Ma ST, Liu PX, Long W, et al. Xuebijing's Anti- 
inflammatory Effect Material Basis and Multi-target Action Effect. Journal of Physical Chemistry 2009;25:2080-6. (in Chinese)

110.Li CY, Zhang XY, Liu s, et al. Current evidence and research prospects of Xuebijing injection in treating Novel Coronavirus-infected Pneumonia (COVID-19). Modernization of Traditional Chinese Medicine and Materia Medica-World Science and Technology 2020;22:242-7. (in Chinese)

111.Kong Y, Lin LL, Chen Y, et al. Mechanism of XueBiJing Injection on Treatment of Coronavirus Disease 2019 Based on Network Pharmacology. Modernization of Traditional Chinese Medicine and Materia Medica-World Science and Technology 2020;22:552-60. (in Chinese)

112.Sun C, Jiang YN, Zhao JM. Overview on epidemiological

Cite this article as: Al-Romaima A, Liao Y, Feng J, Qin X, Qin G. Advances in the treatment of novel coronavirus disease (COVID-19) with Western medicine and traditional Chinese medicine: a narrative review. J Thorac Dis 2020;12(10):6054-6069. doi: $10.21037 /$ jtd-20-1810 characteristics and research of therapeutic drugs of COVID-19. China Journal of Modern Medicine 2020,30:72-9. (in Chinese)

113. Chen J, Wang WQ, Shi CY, et al. Thoughts on prevention and treatment of coronavirus disease 2019 (COVID-19) by traditional Chinese medicine. Chinese Traditional and Herbal Drugs 2020;(5):1106-12. (in Chinese)

114. Duan C, Xia WG, Zheng CJ, et al. Clinical observation of Jinhua Qinggan Granule in treating New Coronavirus Infection Pneumonia. Journal of Traditional Chinese Medicine. Available online: http://kns.cnki.net/kcms/ detail/11.2166.R.20200323.0853.002.html

115. National Administration of Traditional Chinese Medicine. Available online: http://www.satcm.gov.cn/xinxifabu/ meitibaodao/2020-04-17/14712.html 